\title{
A abertura de Timor Português à antropologia social no colonialismo tardio : o papel de Ruy Cinatti
}

The opening of Portuguese Timor to social anthropology in late colonialism: the role of Ruy Cinatti

\section{Cláudia Castelo}

\section{(2) OpenEdition Journals}

\section{Edição electrónica}

URL: https://journals.openedition.org/aa/1926

DOI: $10.4000 /$ aa. 1926

ISSN: 2357-738X

\section{Editora}

Programa de Pós-Graduação em Antropologia Social (UnB)

\section{Edição impressa}

Data de publição: 1 dezembro 2017

Paginação: 83-102

ISSN: 0102-4302

\section{Refêrencia eletrónica}

Cláudia Castelo, «A abertura de Timor Português à antropologia social no colonialismo tardio : o papel de Ruy Cinatti», Anuário Antropológico [Online], v.42 n.2 | 2017, posto online no dia 12 junho 2018, consultado o 18 maio 2021. URL: http://journals.openedition.org/aa/1926 ; DOI: https://doi.org/ 10.4000/aa. 1926

Este documento foi criado de forma automática no dia 18 maio 2021.

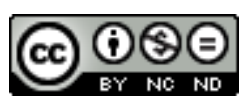

Anuário Antropológico is licensed under a Creative Commons Atribuição-Uso Não-Comercial-Proibição de realização de Obras Derivadas 4.0 International. 


\section{A abertura de Timor Português à antropologia social no colonialismo tardio : o papel de Ruy Cinatti}

The opening of Portuguese Timor to social anthropology in late colonialism: the role of Ruy Cinatti

Cláudia Castelo

\section{NOTA DO EDITOR}

Recebido em 15/03/2017 Aprovado em 12/10/2017

Neste artigo, investigamos os meandros do processo de abertura de Timor Português uma colónia pequena, distante e periférica do império colonial português localizada no sudeste asiático - enquanto terreno de pesquisa antropológica nos últimos anos da presença portuguesa. ${ }^{1}$ Apesar do carácter conservador, nacionalista e imperialista do Estado Novo português (1933-1974), na era da descolonização o território foi visitado e estudado por investigadores estrangeiros de diversas áreas do conhecimento (da história natural às ciências sociais) participando de agendas científicas transnacionais. ${ }^{2}$ Temos evidência empírica que aponta para o papel destacado de Ruy Cinatti (Londres, 1915 - Lisboa, 1986), poeta, engenheiro agrónomo e antropólogo (a partir de 1958) neste processo. O nosso argumento é que Cinatti construiu um status de especialista polivalente de Timor Português que lhe garantiu acesso ao "campo científico". Graças ao reconhecimento do seu sui generis "prestígio" pessoal pelo "campo político" (Bourdieu, 2003), pôde disputar o "monopólio" do conhecimento sobre Timor Português e conseguiu simultaneamente controlar e facilitar a entrada de pesquisadores não nacionais no território e favorecer determinadas pesquisas. ${ }^{3} \mathrm{~A}$ sua acção, que não era imune a dilemas e ambiguidades, deve compreender-se à luz do seu patriotismo e nacionalismo científico, do pragmatismo do regime colonial português num momento em que estava sob forte contestação internacional, bem como das 
debilidades e disputas internas no seio da antropologia portuguesa e do interesse que Timor Português despertava em correntes antropológicas em afirmação na Europa e nos Estados Unidos da América.

Este artigo beneficiou, antes de mais, da excelente e detalhada biografia de Cinatti escrita por Peter Stilwell (1995), que nos reenviou para a consulta do espólio pessoal do poeta. Sustenta-se também em documentação dos arquivos da Juntade Investigaçõesdo Ultramaredo Ministériodo Ultramar, epontualmente em espólios pessoais de correspondentes de Cinatti e em depoimentos orais de investigadores que com ele privaram. Através de contributos teóricos da história das ciências, sobretudo da literatura sobre ciência e império (um balanço historiográfico em Hodge, 2011) mais atenta à circulação, às redes, à localidade e à co-produção de conhecimento, e de conceitos analíticos como ciências de campo (Kuklick \& Kohler, 1996) e especificamente ciências da colecta (Kohler, 2007), pesquisa ao ar livre (Callon, Lascoumes e Barthe, 2001) e intermediação (Raj, 2016), procura pensar as actividades de Cinatti em Timor.

Cinatti começa por ser um naturalista, observador e colector amador, numa colónia periférica de um império em busca de relegitimação. ${ }^{4}$ Porém, o conhecimento baseado em práticas localmente inscritas e o seu carácter proactivo e cosmopolita permitem-lhe alertar e mobilizar especialistas internacionais para a realidade natural, social e humana de Timor Português. O Estado-império sanciona a sua actividade para simular a "ocupação científica" nacional do território e a prioridade científica portuguesa, numa manobra de afirmação e projecção política internacional. Não obstante poder ser considerado um antropólogo irrelevante numa história global da antropologia, a sua agência é uma peça crucial para entender a inscrição de Timor Português nas modernas pesquisas antropológicas então em curso no sudeste asiático, ou seja, para a mudança de paradigma analisada por Hicks (2001a).

Em termos metodológicos, optámos por seguir Cinatti, cuja biografia ilumina simultaneamente a agência individual - que desencadeia processos só a posteriori mediados pelo Estado-império - e o contexto político e científico em que se insere. A abordagem biográfica baseia-se na sugestão de Levi (1989:1334-1335) segundo a qual há uma relação permanente e recíproca entre biografia (sendo que para cada indivíduo há um espaço de liberdade significativo) e contexto (ele próprio incorente e indeterminado) ; e a mudança é precisamente a soma dessas interrelações.

Ruy Cinatti Vaz Monteiro Gomes, oriundo de um meio socioeconómico privilegiado, nasceu em Londres, onde o avô materno era cônsul de Portugal. Porém, fez toda a sua escolaridade na capital portuguesa : os estudos primários nos Pupilos do Exército e no colégio Nun'Álvares; os estudos secundários no Liceu Passos Manuel; e o curso de engenheiro agrónomo no Instituto Superior de Agronomia (ISA). No final do primeiro ano do curso, participou no 1. ${ }^{\circ}$ Cruzeiro de Férias às Colónias, uma iniciativa de $O$ Mundo Português: Revista de Cultura e Propaganda, de Arte e Literatura Coloniais (editada pela Agência Geral das Colónias e pelo Secretariado de Propaganda Nacional) dirigida a estudantes e professores da metrópole (Silva \& Oliveira, 2013 :261-284). Nos meses de agosto e setembro de 1935, visitou as colónias portuguesas da África ocidental : Cabo Verde, Guiné, São Tomé e Príncipe e Angola. Na viagem, tornou-se amigo do director cultural do cruzeiro e de um dos seus adjuntos, respectivamente Marcelo Caetano (professor de direito da Universidade de Lisboa e, à época, comissário nacional da Mocidade Portuguesa) e Orlando Ribeiro (licenciado em geografia e professor da Faculdade de Letras da Universidade de Lisboa a partir da década de 40), bem como de 
José Osório de Oliveira, que integrava o Gabinete de Imprensa e que seria, a breve trecho, um dos principais divulgadores em Portugal da obra do cientista social brasileiro Gilberto Freyre, autor de Casa-grande \& Senzala (1933). O objectivo do cruzeiro era dar a conhecer "a extensão, a importância e a riqueza das colónias visitadas e estreitar as relações culturais e económicas entre a Metrópole e o Império Ultramarino" (O Mundo Português, 1935 :7- 8). Esta experiência de exaltação nacionalista, de contacto com a diversidade geográfica, étnica e cultural do império português, e - não menos importante - de deslumbramento sensorial seria decisiva na opção de Cinatti por uma carreira ultramarina (Stilwell, 1995 :33).

6 Enquanto estudante, Ruy Cinatti integrou a Juventude Universitária Católica (JUC) e despertou para a poesia. A sua particular vivência do catolicismo viria a ser um aspecto central na sua vida, no seu trabalho e na sua obra literária. Autodesignava-se "católico poeta" (Cinatti, 1985: 41). A sua fé religiosa articulava-se com o seu ideal nacional baseado na crença numa suposta vocação universalista de Portugal.

\section{Timor, 1. ${ }^{\text {a }}$ estadia : burocrata e naturalista amador}

7 Terminado o curso e depois de uma primeira experiência profissional na Pan- American Airways como meteorologista (1942-1945), Cinatti foi convidado para secretário e chefe de gabinete do recém-nomeado governador de Timor Português, o capitão Óscar Ruas (1946-1947). Integrava o primeiro governo da colónia após a recuperação da soberania portuguesa (em 1942, o território fora invadido e ocupado por tropas japonesas). Marcelo Caetano, ministro das Colónias, não terá sido alheio ao convite. Em outubro de 1944, Cinatti escrevera-lhe, voluntariando- se para integrar uma expedição portuguesa a Timor, não obstante ter ficado "isento do serviço militar" e de ser "incapaz de pegar numa arma". ${ }^{5}$

Chegado a Timor, o assombro com a natureza foi imediato. Durante sucessivas excursões oficiais, Cinatti conheceu praticamente toda a parte portuguesa da ilha, de avião, de carro e a cavalo. Nessas viagens, podia apenas observar a natureza. Só uma vez, durante a visita ao posto administrativo de Huato-Builico, e a subida ao Mata-MaiLau, pôde colher plantas que se revelariam material importante para o conhecimento de elementos dominantes da vegetação da montanha. Mais tarde, consideraria que essas visões panorâmicas tinham sido necessárias como sínteses iniciais, e deveriam preceder qualquer reconhecimento fitogeográfico (Gomes, 1950b : 47).

Durante as visitas de campo que empreendeu como autodidacta nos seus tempos livres ou as negociadas com o governador com o argumento de que era importante para a colónia realizar-se o estudo sistemático das suas potencialidades agrícolas e florestais, Cinatti colheu e preservou material botânico, xilográfico, malacológico e mineralógico. Sabia que ingleses e holandeses tinham enviado especialistas a Timor desde o início do século XIX e por isso dispunham de colecções que os portugueses não possuíam. Por livre iniciativa e fruto de pesquisas bibliográficas, Cinatti estabeleceu contactos com académicos e especialistas nacionais e estrangeiros, fomentando o conhecimento da flora de Timor Português e procurando obter orientação relativamente às suas práticas de observação e colecta. Visitou o Herbário Nacional e a Junta de Investigações Científicas e Industriais da Austrália, em Melburne, e enviou duplicados dos materiais colectados para estas instituições e para o Instituto de Investigações Florestais de Buitenzorg. Correspondeu-se com Ebertus Meijer Drees (1909-1984), do Instituto 
Florestal de Buitenzorg (Java), H. E. Dadswell, da Divisão de Produtos Florestais da Junta de Investigações Científicas e Industriais da Austrália, H. W. Yaping, director do Instituto de Investigações Florestais de Buitenzorg, A. Kostermans, botânico do mesmo instituto, e C. G. van Steenis, do Rijksherbarium (Leiden), do Instituto Botânico de Buitenzorg e editor da Flora Malesiana, e com Elmer D. Merrill, director do Arnold Arboretum da Universidade de Harvard, especialista em flora tropical do sudoeste do Pacífico. Desses contactos pôde comprovar o interesse que Timor despertava, "não só do ponto de vista botânico, mas também enquanto produtor potencial de recursos essenciais para a indústria dos países vizinhos" (Gomes, 1950a:42).

Com a permissão do governador, Cinatti convidou Meijer Drees para visitar Timor Português. A visita ocorreu em abril de 1947. Durante oito dias, Cinatti calcorreou diversas regiões com o botânico e engenheiro florestal holandês, que o treinou na observação sistemática da paisagem de Timor e na identificação das espécies. Cinatti viria a confessar que essa orientação lhe valera mais do que um ano inteiro de trabalho sozinho (Cinatti, 1950a:53). A interacção com Cinatti também terá sido profícua para Meijer Drees, uma vez que, na pesquisa ao ar livre, "os profanos intervêm junto dos cientistas fazendo-lhes tomar consciência das realidades que lhes escapam" (Callon, Lascoumes \& Barthe, $2001: 136)$.

11 Em correspondência privada com Marcelo Caetano, ao tempo ministro das Colónias, Cinatti denunciou o "empirismo", os erros e as arbitrariedades dos administradores coloniais sobre os nativos, apontando como soluções o estudo do território e das populações por cientistas e a aplicação prática dos conhecimentos por técnicos especializados.

[...] Serão precisos os apóstolos, os etnógrafos, os sociólogos. Apóstolo em Timor é o bispo D. Jaime Goulart, pessoa que melhor conhece o indígena e as suas necessidades. Mas os etnógrafos do tipo de uma Margret Mead, de um Franz Boas, de um Malinowski, etc, simultaneamente antropólogos com a iluminação transparecente de artistas ou sociólogos da têmpera de um Gilberto Freire ou geógrafos à Orlando Ribeiro, ou ainda para não esquecer os antigos aquele meu mestre admirável Alexandre de Humboldt, onde é que estão e porque não vêm ? ${ }^{6}$

12 Noutra ocasião, Cinatti traçou um retrato impiedoso do pessoal administrativo destacado em Timor vindo sobretudo de Angola.

Os administradores são como senhores de grandes quintas cujas entradas são vigiadas por ferozes cães de guarda, não vá algum intruso observar o que nelas se passa e tomar medidas necessárias ao seu desenvolvimento. Para provar este exclusivismo basta notar o abuso dos pronomes possessivos na linguagem empregada. ${ }^{7}$

13 Apresentou também uma pungente denúncia das "barbaridades" da administração portuguesa quando retomou a tutela do território (as condenações em massa e o envio de inocentes para a ilha de Atauro, onde o tratamento era péssimo e a taxa de sobrevivência foi, por conseguinte, muito baixa), da "pancadaria desenfreada" a que nem as autoridades tradicionais escapavam, da "violenta extorsão" dos impostos, da fome generalizada. ${ }^{8}$

Antes, exaltara o espírito do general McArthur e a obra "notável" realizada por soldados e oficiais norte-americanos em plena Segunda Guerra Mundial; obra que se traduziu no "conhecimento da flora, da fauna, da geologia e da etnografia das ilhas do Pacífico onde os americanos lutaram, na aplicação prática desse conhecimento como arma poderosa da vitória". ${ }^{9}$ Apesar de descontente com a situação de Timor Português, 
não gostava de ler afirmações sobre o baixo grau de desenvolvimento da colónia portuguesa, como as publicadas no livro Introducing Australia, do escritor americano Hartley Grattan (ed. 1944). Em parte, é no seu patriotismo que radica a sua vontade de contribuir para uma abordagem científica dos problemas, nomeadamente no que respeita à produção florestal e agrícola.

Cinatti apercebeu-se de que a falta de conhecimento científico sobre os recursos naturais de Timor Português estava na origem de decisões erradas com enormes prejuízos económicos para a colónia. Um dos casos mais graves era o que se estava a passar com o sândalo. Timor era conhecida como a terra do sândalo desde Camões, mas cortes sucessivos e desordenados, o desconhecimento dos processos de cultura e características da espécie tinham levado ao esgotamento dos povoamentos e à tardia proibição dos cortes. Depois da reocupação do território, os administradores, sem conselho técnico, plantavam em formações puras milhares de pés de sândalo que morriam passado um mês. O número de árvores existentes já não tinha valor comercial, embora o preço pago em Hong Kong pela madeira de sândalo fosse muito elevado. 0 Timor holandês, que também tinha sofrido com a guerra, exportava cerca de 100 toneladas por ano e estava em vias de aumentar essa cifra. Ali havia uma organização modelar dos serviços técnicos, que incluíam agrónomos, silvicultores, geólogos e botânicos. Em Timor Português, só em 1947 - graças a Cinatti - se "descobriu" que o sândalo era um parasita. Cinatti informou-se na Austrália junto das autoridades especializadas no assunto; e em Koepang foi-lhe oferecido um livro de 1925 feito por técnicos de Buitenzorg que estudava o sândalo de Timor e indicava os hospedeiros naturais que abundavam na ilha e os métodos de cultivo. ${ }^{10}$

Jorge Dias (1996), no prefácio a Um cancioneiro por Timor, reflecte sobre a passagem de Cinatti de poeta-naturalista a antropólogo ainda sem profissionalização. 0 próprio Cinatti, na sua correspondência privada, em relatórios inéditos e em trabalhos publicados, dá conta desse percurso : a observação do mundo natural aproximou-o dos homens, e despertou o seu interesse pela cultura dos timorenses e pelas relações que estabeleciam com o meio ambiente. Num relatório enviado à Comissão Executiva da Junta das Missões Geográficas e de Investigações Coloniais (JIC) em março de 1949, explica que

foi o convívio, mais do que qualquer preocupação intelectual de ordem intrínseca, que [o] levou a receber a lição de geografia humana, etnografia, filologia e, portanto, de solidariedade, que Timor nos oferece. Com ela, [recebeu] a força que define o defensor de uma causa amada. A simples colheita de plantas obriga a desviar a atenção para fenómenos que outras funções estão longe de valorizar. Foi assim que, sem o saber, [esteve] seguindo os métodos de uma ciência nova: a etnobotânica agronómica, que em certos países coloniais já deu provas fundamentadas de utilidade na fixação, educação, elevação do nível de vida do indígena e do europeu (Gomes, 1949 :49).

17 A influência do antropólogo social australiano A. P. Elkin (1891-1979) (Wise, 1985) foi decisiva nesta "metamorfose" e tem passado algo despercebida (apesar de Oliveira, 2006 :76-77). Elkin era um pastor anglicano e, à data, o mais destacado antropólogo social australiano, professor e responsável (desde 1934) pelo Departamento de Antropologia da Universidade de Sydney; departamento que desde a sua criação, em 1926, se vinha dedicado a orientar a administração das populações nativas e a treinar funcionários administrativos para os territórios australianos da Papua e Nova Guiné (Anderson, 2006:248). Fizera a tese de doutoramento no University College de Londres, sobre mito e ritual aborígene (1927). De volta à Austrália, fez trabalho de campo numa 
expedição organizada por Alfred Radcliffe-Brown e financiada pelo Australian National Research Council e tornou-se defensor de uma "antropologia aplicada". Entre 1933 e 1962, foi presidente da Association for the Protection of Native Races, uma instituição que trabalhava em prol da melhoria das condições de vida dos aborígenes. Acreditava na vantagem do envolvimento dos antropólogos na formulação de políticas públicas nativistas. A sua acção política em prol da assimilação dos nativos veio a ser rotulada de paternalista.

Não sabemos exactamente quando Cinatti leu pela primeira vez The Australian aborigines: how to understand them (1938), mas temos provas de que em 1946 já conhecia o livro, pois encontramos na sua correspondência paráfrases do prefácio.

O indígena não me interessa apenas como instrumento de trabalho, os seus costumes não devem ser considerados unicamente sob o ponto de vista de curiosidades culturais. A sua cultura interessa-me, sim, como afirmação de uma vida que se prolonga há não sei quantos séculos e que está perigosamente sujeita à destruição, mercê de um contacto de costas voltadas. ${ }^{11}$

É impossível não perceber a apropriação do seguinte excerto :

I do not regard the Aborigines as interesting survivals of man's early ancestors, nor their customs as cultural curiosities [...]. I am concerned with their culture as a means of life worked out during the past centuries - a culture which is being strained to breaking point by contact with ourselves (Elkin, 1938:viii).

Cinatti afirma que está errado avaliar "a civilização de um povo pelo seu modo de vida e possessões materiais", ${ }^{12}$ tal como Elkin (1938 :viii) : "we are apt to make the mistake of thinking that because a people is primitive and poor in material possessions it has a very elementary form of social order and religious life". Acusa os portugueses que vão para Timor ganhar dinheiro de levarem "longe de mais o mito da raça inferior, simplesmente porque essa raça não procede de acordo com o que nós convencionámos chamar civilização. [...] Mas essa raça é bem adulta ; os seus membros não pensam como crianças, [...] mas como personalidades sociais responsáveis e mantenedoras de vida social, económica e religiosa de comunidade". ${ }^{13}$ Mais uma vez, reutiliza Elkin (1938:viii) : "some folk carry the methaphor of child-race too far. [...] Its grown men and women, however, are adults; they do not think as children but as social personalities who are responsible for the development and maintenance of the social, economic and religious life of their community". Anos mais tarde, numa carta que escreve a Elkin e a que voltaremos adiante, Cinatti confessa que há muito vinha "lendo e relendo" o seu livro sobre os aborígenes australianos e "reunindo dicas" que orientavam as suas relações com os povos timorenses.

Entretanto, no fim da primeira estadia em Timor, Cinatti regressou a Lisboa. Graças a um subsídio da JIC, pôde dedicar-se a trabalhos de gabinete referentes aos materiais colectados que havia remetido ao Instituto Botânico da Faculdade de Ciências de Lisboa, ao Centro de Botânica da JIC e ao ISA, e elaborar um inventário dos recursos económicos da ilha (1949-1950). Em 1950, apresentou o seu relatório de final de curso no ISA, com o título Reconhecimento em Timor. Nesse ano, a JIC publicou três trabalhos seus : Esboço histórico do sândalo no Timor português (1950a), Explorações botânicas em Timor (1950b) e Reconhecimento preliminar das formações florestais no Timor português (1950c). As ideias bebidas em Elkin, que já apareciam na correspondência privada, surgem agora nas suas publicações - "o Timorense é um ser adulto, pensante, com uma personalidade social definida e responsável" (1950b :45) - e vão alimentar o seu programa de acção na sua segunda estadia em Timor. 


\section{Timor, 2. a estadia : entre a agricultura e o apelo antropológico}

21 Em 1951, Cinatti voltou a Timor como agrónomo da recém-criada Repartição de Agricultura, Veterinária e Indústria Animal. Supostamente o ministro do Ultramar Sarmento Rodrigues dera-lhe permissão para "andar a monte, conviver com o indígena e não tocar sequer num papel", mas é de imediato nomeado chefe da repartição, vendose "condenado" a burocracias de gabinete (Stilwell, 1995 :199-200). A breve trecho, a relação privilegiada com o ministro garantiu- lhe condições para viajar pelo território e prosseguir a actividade de colector subsidiado da agora renomeada Junta das Missões Geográficas e de Investigações do Ultramar (JIU). Ia remetendo a professores e instituições da metrópole os resultados das suas colheitas de plantas, madeiras, minerais, solos, líquenes, búzios e corais. Também enviava duplicados de espécimes botânicos para herbários na Austrália e Indonésia e aproveitava deslocações oficiais a países vizinhos para empreender pesquisas botânicas.

Em finais de agosto de 1953, António Augusto Mendes Correia, presidente da JIU e responsável pela secção antropológica da instituição, e António de Almeida, chefe da Missão Antropológica de Timor, convidaram Cinatti a acompanhá-los numa excursão pelo território (Stilwell, 1995 :212). Mendes Correia deslocou- se a Timor para averiguar das condições para a instalação de um centro de estudos local (Matos, 2012 :204) e aproveitava para visitar algumas regiões cujos grupos étnicos lhe interessavam. Por seu turno, António de Almeida aguardava a chegada do material de campanha para dar início aos trabalhos de campo da MAT, cujo programa antropológico correspondia ao "antigo conceito totalizante da ciência do Homem", englobando a pré-história, a antropologia física e a etnografia (Oliveira, $2006: 61$ ). No entanto, a recolha de informação deveria servir o propósito primordial da Missão : a elaboração da carta etno-linguística de Timor português (sobre a MAT, ver Schouten, 2001). A excursão pelo interior, com as duas principais figuras da antropologia colonial portuguesa da época, despertou em Cinatti o interesse pela pré-história e pela cultura material de Timor e a vontade de obter formação nessas matérias. Elaborou com Mendes Correia uma pequena notícia sobre as pesquisas arqueológicas empreendidas em Timor - notícia também assinada por António de Almeida, que a apresentou ao 4. Congresso de PréHistória do Extremo Oriente, realizado em Quazon (Filipinas) de 16 a 28 de novembro de 1953. Na ocasião, confrontou-se com a falta de preparação científica de António de Almeida no domínio da arqueologia. Na sequência do diferendo entre António de Almeida e Duarte Mendes, oficial em serviço em Timor e amigo de juventude de Cinatti, que rebateu afirmações do antropólogo físico e deputado à Assembleia Nacional por Timor ao Diário Popular, por deturparem a realidade, nomeadamente no que respeita ao conhecimento científico do território, Cinatti criticou-o por colocar as conveniências políticas acima da investigação científica (Stilwell, 1995 :220). A este momento remonta o afastamento de Cinatti relativamente a Almeida, com quem viria a disputar autoridade científica e ascendente sobre o conhecimento de Timor.

No 8.. Congresso de Ciência do Pacífico, que decorreu em simultâneo com o 4.ำ Congresso de Pré-História, Cinatti apresentou uma comunicação sobre "Timor Português: terra de contrastes (vegetação e agricultura)", na qual valorizava os conhecimentos e as práticas agrícolas dos timorenses e criticava a aplicação, pela 
administração colonial, de métodos agrícolas europeus (Oliveira, 2006 :76). A. P. Elkin assistiu à comunicação e aprovou as conclusões de Cinatti - como vimos atrás, em parte inspiradas na sua obra - e "estabeleceu-se uma relação de cordialidade" entre ambos, potenciada por partilharem visões próximas nomeadamente sobre "o papel da Igreja (Católica e Anglicana) na defesa dos povos indígenas e na oposição a políticas coloniais de assimilação forçada" (Oliveira, 2006 :77).

No final do ano seguinte, Cinatti viajou pelo interior durante quatro semanas com o botânico holandês van Steenis, editor-geral da Flora Melanesiana, com quem mantinha correspondência desde 1947 e que conhecera pessoalmente durante o congresso nas Filipinas. Em 1951, em carta ao presidente da JIU em que dera conta dos contactos com van Stein e do desejo deste de visitar Timor, afirmara que era um exemplo do "interesse despertado por aquela possessão ultramarina nos meios científicos estrangeiros" e esclarecia: "não se trata apenas de uma devoção legítima à causa da ciência, mas, sobretudo, uma obrigação que nos prestigia, inclusive no campo político" (ERC, carta de RC para o presidente da JIU, 24 de julho de 1951). A experiência de aprendizagem com o "mestre dos mestres botânicos" foi gratificante e o seu incentivo directo veio a traduzir-se na publicação de "Vocabulário indígena de algumas espécies timorenses" na revista da JIU, Garcia de Orta (1954).

A correspondência e os documentos profissionais (informações, propostas e relatórios) existentes no espólio de Ruy Cinatti permitirão um melhor entendimento da sua acção nos serviços de agricultura, até agora abordada com base no trabalho do engenheiro agrónomo Hélder Lains e Silva, que visitou Timor Português no âmbito de uma missão científica da Junta de Exportação do Café (Shepherd, 2013; Shepherd \& McWilliam, 2014 ; Silva, 1956). Durante a pesquisa que realizou em Timor, Lains e Silva pôde contar com a companhia, os conhecimentos e as "lições de timorismo" de Cinatti (Silva, 1956 :XIII), que, à frente da Repartição de Agricultura, vinha aperfeiçoando o seu conhecimento sobre os modos de vida e as práticas agrícolas dos timorenses. Tudo indica que as propostas para o cultivo do café em Timor apresentadas por Lains e Silva (1956) foram pensadas com Cinatti e fundamentadas num conhecimento localmente baseado ("place-based knowledge" em Mehos \& Moon, 2011 :44) obtido com este. Estas propostas, anteriormente apresentadas por Cinatti ao governador, capitão Serpa Rosa, não teriam tradução na prática. Mesmo sendo chefe da Repartição de Agricultura, Cinatti esbarrou sistematicamente com o poder dos administradores coloniais, que tomavam decisões sem qualquer fundamento científico (por exemplo, quanto à época $\mathrm{e}$ sementeira do milho) e não seguiam as suas instruções técnicas. No relatório de uma visita de inspecção à região do café (Ermera, janeiro de 1955), Cinatti mostrava o erro de se abrirem picadas para o plantio da Albizzia e mais tarde do cafeeiro, ao correr das linhas de maior declive, em zonas de relevo acidentado. Acrescentava que o absurdo era indesculpável, pois em Timor havia tradições muito antigas de protecção da terra e das culturas contra os efeitos da erosão (apud Stilwell, 1995 :224).

Cinatti considerava que, como agrónomo, podia contribuir para a melhoria das condições de vida dos timorenses. Pediu então conselho a académicos estrangeiros de reconhecido mérito nas suas áreas de estudo. Em carta a A. P. Elkin, Cinatti confessavase muito entusiasmado com o novo campo da antropologia aplicada, capaz de interessar à administração e ao desenvolvimento dos povos nativos, de que tivera conhecimento pela leitura de Social anthropology in Melanesia: a review of research, cuja Parte III 
estabelecia "Principles of a plan of anthropological research in Melanesia related to native walfare and development" (Elkin, 1953).

O cargo que ocupava no quadro técnico da administração colonial não lhe permitia fazer o curso da Universidade de Sydney, mas Cinatti tinha intenção de aplicar alguns métodos antropológicos nas instruções aos seus subordinados dos serviços de agricultura e florestas.

My intentions are, however, very definite as to the application of some anthropological methods to the instructions I give to my officers. With this in mind, I am continually recommending their full attention to the indigenous ways, their reaction to new field practices, and the reason for this and that.

Briefly, I am trying to base any kind of agricultural development on the level of their culture. ${ }^{14}$

Ao contrário da maioria dos funcionários administrativos em Timor, Cinatti não considerava os timorenses seres inferiores ou preguiçosos, mas "seres humanos iguais a si", "com personalidade social" (tal como Elkin a propósito dos aborígenes australianos), e reconhecia a racionalidade das suas práticas agrícolas e a necessidade de as aperfeiçoar e não de as substituir por práticas europeias. Era especialmente crítico quanto às plantações em regime de monocultura (café, coco e borracha) devido à deestruturação social que acarretavam. Pedia a orientação de Elkin na preparação de inquéritos agroantropológicos que pudessem vir a comprovar uma tese que havia desenvolvido a partir de "pura observação" e alguns "insights". Considerava que o mais alto nível de unidade social em Timor Português se observava onde a influência das Missões católicas era mais forte e onde, por esta mesma razão, os processos agrícolas tinham estado a salvo da acção drástica de administradores e fazendeiros em prol do desenvolvimento económico. O elemento espiritual introduzido pelas Missões evidenciou as capacidades do nativo indígena médio. Nestes lugares, o policultivo dentro de pequenas propriedades autossustentáveis era a base da unidade social - um sinal de progresso social, que se evidenciava até numa melhor condição física dos timorenses. Noutros locais, onde a influência administrativa colonial era mais forte, a monocultura em larga escala podia tornar o nativo mais rico, mas não acarretava promoção social num sentido cultural ou civilizacional.

Na resposta, Elkin mostrava-se agradado com a forma como Cinatti estava a pensar os problemas práticos da mudança social e cultural em Timor Português e dizia concordar com a tese de Cinatti sobre o efeito positivo das Missões católicas na vida agrícola económica e social. Afirmava que gostaria de o ter no Departamento de Antropologia de Sydney um ano ou dois, mas percebia as dificuldades de Cinatti. Sugeria-lhe que entrasse em contacto com R. L. Pulsford, um funcionário dos serviços agrícolas da administração da Papua e Nova Guiné, que recebera formação em antropologia. Salientava, por fim, que "the native peoples must adopt and adapt the new ways in their own way. They can be helped, but cannot be forced or rushed" ${ }^{15}$

Nesta segunda estadia em Timor, Cinatti voltou a confrontar-se com o impacto destrutivo do domínio colonial no território e nas populações. Denunciou as arbitrariedades, extorsões e injustiças da administração colonial a vários correspondentes, mormente aos que tinham altas responsabilidades governativas. 0 seu antigo colega da JUC, Carlos Krus Abecasis, subsecretário de Estado do Ultramar, por insistência sua, viria a deslocar-se em visita oficial a Timor Português em 1956. Diante das péssimas condições de vida e de trabalho dos timorenses, sujeitos a pesados impostos, à venda compulsiva de produtos a baixo preço, à violência física para 
incremento do trabalho, deixou instruções ao governador para acabar com os castigos corporais e demais abusos (Stilwell, 1995:281); porém, sem grande impacto nas camadas inferiores da administração colonial que contactava directamente com as populações.

Perante a crescente contestação internacional a que Portugal esteve sujeito no pósSegunda Guerra Mundial, na fase final do domínio português, ter-se-á assistido em Timor Português, ainda que num nível mínimo, aos primeiros passos em direcção a um desenvolvimento negociado (Shepherd, 2013). Está ainda por explorar o impulso que Cinatti deu nesse sentido. Inspirado na obra, na acção e eventualmente na postura moral de Elkin, Cinatti defendia um desenvolvimento capaz de conciliar ciência e ética. Pretendia que a economia de Timor não fosse "apenas de exploração, mas, simultaneamente de conservação e de valorização" (apud Stilwell, 1995:209). Concebeu e projectou esse programa de desenvolvimento humanista em correspondência com amigos e conhecidos do campo político, em correspondência e relatórios enviados a colegas e à JIU (para o interior do campo científico) e no manifesto "Em favor do timorense" (1956), que publicou na revista Cidade Nova (para um público mais alargado).

\section{Entre Lisboa, Oxford e Timor. na senda da profissionalização em antropologia}

De licença na metrópole desde inícios de 1956, Cinatti desdobrou-se em diligências para ingressar nos quadros da JIU e estudar antropologia cultural e social, formação que não estava disponível em Portugal (Leal, 2006).

Eu vinha de Timor, muito interessado em estudar Antropologia para fazer dela um instrumento que me permitisse intervir directamente na ordem prática, no chamado "welfare" das minhas gentes de Timor, na sua valorização como seres humanos meus irmãos. ${ }^{16}$

Em carta ao ministro do Ultramar, de 29 de outubro de 1956, pedindo o seu ingresso "na JIU ou noutro organismo afim, por onde possa ser-lhe facultada a frequência de um curso de Antropologia Cultural, de preferência em Inglaterra", afirmava:

concomitantemente aos trabalhos inerentes ao seu cargo oficial e de colector, debruçou-se sobre o meio humano de Timor, com o carinho e entendimento que sempre lhe mereceram homens da sua ou de outra raça, menos ou mais civilizados, buscando na sua duplice qualidade de português e de agrónomo uma adequação dos processos de relação e de cultura à tradição funcional e à mentalidade do timorense. Deste recebeu, por sua vez, claros e afectivos ensinamentos conducentes a uma síntese de acção mútua, da qual a Administração só pode vir a ser favorecida. As suas tentativas mereceram a aprovação e o encorajamento dos professores de Antropologia e Sociologia da Universidade de Sydney, organismo que detém sob orientação directa o complexo problema das relações sociais entre os povos do Sudoeste do Pacífico. ${ }^{17}$

34 No seu desejo de aplicar os métodos antropológicos e sociológicos à administração colonial, percebe-se a sintonia com Elkin, que não tinha nenhum interesse em pesquisas bioantropológicas, priorizava o estudo dos efeitos dos contactos entre europeus e aborígenes, que encarava enquanto personalidades sociais em contextos contemporâneos desafiantes, e acreditava que a antropologia social podia facilitar a sua adaptação e promoção cultural (Anderson, 2006:248-249). 
35 Finalmente, em 1957, Cinatti entrou para a JIU, graças ao parecer favorável do subsecretário de Estado do Ultramar, o seu amigo Carlos Krus Abecasis. Ficava "adstrito à Comissão Executiva na qualidade de informador imediato sobre assuntos de Agronomia e Silvicultura, Antropologia e História, nomeadamente de Timor e do Sudeste Asiático". A Comissão Executiva era então presidida por João Carrington da Costa, a quem Abecasis viria a suceder em 1961. Graças a uma bolsa da JIU, foi estudar antropologia social em Inglaterra (refira-se que Elkin já se havia aposentado da Universidade de Sydney em 1956). Depois de uma curta passagem por Londres, Cinatti optou por fazer o curso em Oxford. Obteve o diploma em etnologia e antropologia social em 1959, sendo aconselhado pelo diretor do curso, Evans-Pritchard, a prosseguir a sua formação. Com autorização da Junta, Cinatti inscreveu-se no curso de bacharel em literatura.

Começou a trabalhar numa tese com um objeto muito abrangente - provisoriamente intitulada "The ecology, history and material culture of Portuguese Timor, with special reference to the native habitat" -, baseada sobretudo em investigação bibliográfica e aproveitando a circunstância de chefiar a Missão de Estudo do Habitat Nativo de Timor. Contudo, em finais de 1959, o seu tutor, T. K. Penniman, director do Pitt-Rivers Museum, transmitiu-lhe que a sua pesquisa tinha fôlego para um PhD. Em junho de 1960, recebeu a notificação da sua aceitação como estudante de doutoramento. Durante a estadia em Oxford, foi amiúde a Londres para se encontrar com Anthony Christie, especialista em arqueologia do Sudeste asiático, e com o historiador Charles Boxer ; foi duas vezes à Holanda, onde frequentou o Instituto de Etnologia da Universidade de Leiden, e recebeu "ensinamentos e esclarecimentos preciosíssimos" dos professores F.D.K. Bosch, Th. P. Galestin e G. W. Locher; e passou por Paris, por ocasião do Congresso Internacional de Antropologia, tendo-se encontrado "com o professor R. Heine-Geldern, da Universidade de Viena, um dos maiores especialistas dos estudos culturais do Sudeste da Ásia". ${ }^{18}$ Durante os seus estudos em Oxford, teve discussões com Rodney Needham, cuja visão da antropologia não partilhava, sentindo-se mais próximo de Evans-Pritchard :

depressaaprendique, emboraemúltimaanálisequalquerespéciedeconhecimento seja forçado à acção, não era a sua aplicação directa que interessava a escola de Oxford. Daí as minhas fúrias com o[Rodney] Needham : eu insurgia-me com a hipótese de ver os meus Timorenses tratados como polichinelos para bel-prazer de uns tantos "naturalistas" da espécie humana. Daí o meu desacordo com o funcionalismo, com Durkheim à frente, e a aplicação do método das ciências naturais. O EvansPritchard, já então em completa dissensão e todo voltado para a História (leia o seu ensaio "Anthropology and History"), apreciou-me, sobretudo, pelo calor humano que eu dava as minhas afirmações. ${ }^{19}$

37 Atendendo a que pouco se conhecia do Timor português e perante as suas "descobertas", Cinatti foi muito encorajado pelos seus professores. Graças à pressão de Evans-Pritchard junto da JIU, Cinatti pôde fazer uma estadia de campo em Timor entre dezembro de 1961 e finais de 1962. Foi também com o apoio de Evans-Pritchard que Cinatti conseguiu sucessivos adiamentos do prazo de entrega da sua tese, que nunca viria a concluir.

38 A disputa de autoridade com António de Almeida, latente desde 1954, vai manifestar-se nalgumas ocasiões. Por exemplo, perante a informação produzida por Cinatti em $21 \mathrm{de}$ março de 1964 para a Comissão Executiva da JIU, delimitando os campos e a definição das atribuições dos centros de Antropobiologia (dirigido por António de Almeida) e de 
Antropologia Cultural (dirigido por Jorge Dias). Nessa informação, Cinatti põe em causa a capacidade científica do Centro de Estudos de Antropobiologia da JIU para efectuar pesquisas no âmbito da antropologia social, uma vez que "todos os investigadores daquele centro ignoram as modernas concepções de investigação antropológica britânica e francesa" (apud Oliveira, 2006 :98). António de Almeida discorda "em absoluto tanto no plano teórico como prático" e fica bastante ofendido com as afirmações mais incisivas de Cinatti, que considera uma tentativa de acantonar a suas investigações apenas no domínio da antropologia física. ${ }^{20}$

Ainda em 1964, Cinatti pediu autorização ao presidente da CE da JIU para se deslocar à Suíça e à Holanda em comissão eventual de serviço, por um período de cerca de um mês, para se encontrar com especialistas em pré-história e história e sociologia do sudeste asiático e visitar museus e departamentos universitários de etnologia.

$\mathrm{Na}$ Suíça haveria particular vantagem em contactar, em Basileia, com o Prof. Alfred Bühler, director do Museu de Etnologia daquela cidade.

O Prof. Bühler foi o primeiro investigador da Pré-História do Timor Português, tendo durante a sua estada nesta Província, adquirido grande colecção de objectos para o Museu de que é director. [...]

$\mathrm{Na}$ Holanda, o signatário propõe-se visitar os departamentos de Etnologia das Universidades de Leiden e de Utrecht e entrar em contacto com os Profs. T. P. Gallestin [Galestin], Josselyn de Yonj [Jong], R. Koenigswalde von Heekeren que são, na Europa, as maiores autoridades nos domínios Pré-História e História e Sociologia do Sudeste Asiático.

Caso o período pedido o permita seria ainda intenção do signatário visitar, em trajecto, o Museu de Etnologia de Copenhaga (Prof. Briket-Smith), o Museu do Homem, em Paris (Prof. Louis Berthe que estudou os Bunak timorenses) e ainda Oxford onde o prendem relações universitárias que têm que ver com o seu futuro doutoramento. ${ }^{21}$

Com parecer favorável da presidência da CE da JIU e do Gabinete de Negócios Políticos do Ministério do Ultramar, Cinatti foi autorizado a deslocar-se àqueles países. No âmbito dessa deslocação, encontrou-se em Paris com Louis Berthe (especialista em organização social, estudo do parentesco e etnomusicologia) e em Oxford com David Hicks e James Fox, doutorandos em antropologia social. Estes encontros foram decisivos para a abertura de Timor à antropologia moderna.

David Hicks pretendia fazer trabalho de campo em Timor português por causa do interesse que o seu orientador - Rodney Needham - lhe incutira relativamente a alianças matrimoniais assimétricas. Etnógrafos holandeses durante o período colonial holandês tinham chamado a atenção para a existência de sistemas dessa natureza em várias partes do leste da Indonésia, e sua existência no Timor Português tinha sido observada na literatura em inglês do século XIX pelo naturalista Henry Forbes (1884) (Hicks, 2017). O antropólogo francês Claude Lévi-Strauss, com o seu Les structures élémentaires de la parenté (1949), Edmund Leach (1951), JPB Josselin de Jong (1952) e Needham (1962) introduziram o tópico no mainstream teórico da disciplina e despertaram a atenção de jovens pesquisadores como Hicks (2017), que desejava testar algumas das suas ideias.

Needham, sabendo da visita de Cinatti a Oxford, aconselhou Hicks a pedir- lhe ajuda para obter autorização do governo português para fazer trabalho de campo em Timor. Cinatti disse a Hicks que iria falar com Krus Abecasis, mas não lhe contou que também se comprometera a ajudar um antropólogo francês no mesmo sentido. 
Ele não pôs nenhuns problemas relativamente à minha ida a Timor, o que na época era um assunto sensível, a guerra estava a decorrer em Angola e Moçambique. Timor era relativamente tranquilo, ou completamente tranquilo, mas mesmo assim havia um sentimento anticolonial no ar na ONU, e é compreensivel que o Governo português fosse muito cauteloso em autorizar a ida de estrangeiros. Eu não sabia naquela altura que Cinatti estava a planear uma missão franco-portuguesa a Timor português em 1966. Ele nunca me mencionou isso; mas ele referiu que um antropólogo americano tinha pedido autorização ao Governo português para fazer trabalho de campo em Oe-Cussi e que ele tinha aconselhado o governo a não conceder permissão, porque ele podia ser um agente da CIA (Hicks, 2011b).

James Fox, também apresentado por Needham a Cinatti, disse a este último que tinha interesse em estudar os Galoli de Timor português mas, na altura, estava prestes a partir para a Indonésia para estudar os Roti, o que aconteceu em 1965 e 1966 e deu origem à sua tese de doutoramento em Oxford. Mais tarde, escreverá a Cinatti lembrando que gostaria de estudar os Galoli de Timor português (sobretudo gostaria de estudar um povo com um sistema prescritivo de alianças matrimoniais) a partir de junho de 1969 e pedindo o seu conselho e ajuda. ${ }^{22}$

Louis Berthe, que já havia estudado os Bunak do lado indonésio e português da fronteira de Timor, recebeu o incentivo e o conselho pessoal de Cinatti para escrever à junta "com vista a uma nova missão a Timor, agora exclusivamente dedicada à parte portuguesa". ${ }^{23}$ Após troca de correspondência particular entre Berthe e Cinatti, o investigador francês enviou uma carta ao presidente da CE da JIU expondo seu desejo de continuar em Timor as pesquisas etnográficas, musicológicas e linguísticas que levou a cabo em 1958 e $1959 .{ }^{24}$ Sem resposta da JIU, Louis Berthe confrontou Cinatti :

devo concluir que em definitivo você deu preferência a um inglês ou a um americano?

Ficaria muito feliz se você quisesse pôr-me ao corrente do resultado das minhas cartas e das suas démarches. E não se esqueça de vir ver-me se passar por Paris :

você sabe que a minha mulher e eu próprio ficaremos sempre muito felizes de acolhê-lo na nossa casa.

O financiamento necessário para a viagem e a permanência de quatro meses em Timor português foram solicitados ao CNRS. Se de qualquer forma, apesar do seu convite, não pudermos lá ir, voltaremos certamente à Indonésia. ${ }^{25}$

Finalmente, a 3 de novembro de 1965, Carlos Krus Abecasis respondeu a Louis Berthe, transmitindo-lhe que, na sequência da informação de Cinatti e de acordo com as linhas de pesquisa da JIU, a decisão do plenário foi a de aprovar uma missão etnológica a Timor português dirigida pelo investigador francês. Segundo Cinatti, "para [...] ligar, por prudentes laços políticos e administrativos, a missão francesa à investigação portuguesa, ficou assente que esta Junta [de Investigações do Ultramar] participaria financeiramente nos encargos da missão. A missão passaria, deste modo, a ser considerada como luso-francesa e não apenas francesa". ${ }^{26}$

Em 15 de fevereiro de 1966, o diretor-adjunto do CNRS oficializou a missão etnolinguística a Timor português perante a JIU, e agradeceu em nome daquele organismo a cooperação da investigação científica portuguesa numa missão conjunta, no quadro da Recherche Coopérative sur Programme (RCP) n.- 61 do Centre de Recherche sur Ásie du Sud-est et le Monde Indonésien, cujo tema era "Atlas etnolinguístico do Sudeste da Ásia", dirigida por George Condominas. Confirmava que a missão poderia integrar um especialista em mitos indonésios, um especialista em 
cultura material, um etnobotânico, um linguista e um especialista em antropologia social, conforme o projeto de missão remetido a Lisboa por Louis Berthe.

Segundo Ruy Cinatti, Louis Berthe comprometeu-se em fevereiro a limitar o âmbito do trabalho da missão à região etnolinguística Kairui (Henri e Maria Olímpia de Campagnolo), à região dos Bunak (Louis Berthe e Claudine Friedberg) e a uma região limítrofe entre os Bunak e os Kemak (Brigitte Clamagirand). Terão sido estas as indicações enviadas à JIU. A equipa chega a Timor a 20 de abril de 1966. 0 governador do território já estava informado de que a "missão de estudos de etnolinguística e antropologia social do CNRS com a colaboração da JIU", dirigida por Berthe e projetada de abril a agosto, fora autorizada pelo ministro do Ultramar, que Cinatti acompanharia a missão nos últimos dois meses e que, até lá, sugeria que Alferes Arez desempenhasse essa função, e que deveria conceder as "facilidades usuais, incluindo intérpretes de línguas kemak e kairui”"27.

Por despacho do ministro do Ultramar, Ruy Cinatti foi enviado a Timor para acompanhar durante os meses de agosto e setembro de 1966 os trabalhos da missão franco-portuguesa. Aproveitou também a ocasião para visitar David Hicks, em Viqueque. Quando chegou a Timor, Cinatti ficou desagradado por os Campagnolo terem mudado de terreno de pesquisa, entrando no território adstrito à investigação de David Hicks (localidades de língua tétum) sem o seu conhecimento e anuência. Não terá sido apenas por ter sido desautorizado. Por um lado, Cinatti considerava Laclubar a melhor porta de entrada na região dos Kairui ; por outro, considerava os Fataluku o povo mais interessante de Timor: devido às casas fabulosas em que viviam, construídas sob pilares, deviam ter uma organização social fascinante (Hicks, 2011b). Por essa razão, Cinatti pretendia reservar o estudo dos Fataluku para um etnólogo português ou eventualmente para si próprio. No entanto, Cinatti chegou a oferecer a Hicks a possibilidade de estudar os Fataluku (Hicks, 2011b).

David Hicks, que se instalara com a família em Viqueque para estudar os Tetum, ficou desapontado porque a comunidade que Cinatti lhe atribuíra não praticava a troca generalizada, uma instituição envolvendo alianças matrimoniais (conhecida como barlaque em Timor) que lhe interessava estudar.

Os nossos vistos estipulavam, é claro, que eu tinha que estudar apenas as populações falantes de Tetum, de Viqueque, no leste, até Suai, no oeste, cobrindo o concelho de Manatuto. Que grupo tem troca generalizada, perguntou-me [Cinatti]. Eu respondi : os Cairui e Makassai, entre outros. Quase todos os grupos étnicos. Aprende Cairui e aprende Makassai, disse-me Cinatti. Ou vem comigo até Loré, acrescentou. Podes trabalhar lá. Eu expliquei que já tinha começado a aprender Tetum e que me tinha estabelecido em Viqueque. Eu gostava das pessoas. Eu disse que não podia fazer isso, eu estava a aprender a língua. Eu queria ficar. Bem, disse ele, dei-te a tua chance; dei-te a tua oportunidade. Ele estava a marcar a sua posição. Nenhumas queixas mais tarde ! E assim partiu para Loré (Hicks, 2011b).

Outra surpresa com que Hicks se confrontou no terreno, depois das primeiras pesquisas, foi que as populações de Viqueque não falavam apenas Tetum, ao contrário do que Cinatti lhe transmitira ; falavam também Kairui, Makassai, Nauete e Wai Ma'a.

51 Importa referir que a missão etnológica a Timor só foi autorizada porque o Gabinete de Negócios Políticos do Ministério do Ultramar deu parecer favorável, uma vez que "estava assegurada a defesa dos nossos interesses políticos", "desde que se confirme que os cientistas franceses se encontram nas condições de idoneidade que não podemos deixar de exigir". ${ }^{28}$ Tanto Cinatti como a JIU e os responsáveis políticos teriam preferido 
que os "estudos etnológicos propostos [...] das etnias portuguesas de Timor fossem executados por portugueses", mas em Portugal não se vislumbrava quem pudesse integrar a missão : não havia ninguém com formação, apetência e/ou disponibilidade nos organismos da Junta. Jorge

Dias já não estaria em condições físicas para um trabalho de campo intensivo num terreno que desconhecia, a sua pequena equipa no Centro de Estudos de Antropologia Cultural estava mais direccionada para o trabalho etnográfico em Portugal metropolitano, e ainda não fora criado o curso de antropologia no ISCSPU (Leal, 2006).

Apesar de desentendimentos entre Cinatti e Berthe relativamente às regiões de Timor atribuídas a cada investigador, Cinatti sempre reconheceu a excelência do trabalho daquela missão. ${ }^{29} \mathrm{E}$, por seu turno, aquando das conversações entre o CNRS e a JIU para uma segunda missão (1969-70), agora chefiada por Claudine Friedberg (viúva de Louis Berthe, falecido em janeiro de 1968), os membros da equipa mostram-se muito agradecidos a Ruy Cinatti, "qui nous transmettant son amour pour Timor fut l'instigateur de notre équipée scientifique sur cette île et nous a toujours soutenus dans nos recherche". ${ }^{30}$

54 No final dos anos 1960 e inícios dos anos 1970, Cinatti, por obrigação do cargo que ocupava na JIU, continuou a ser ouvido sempre que algum pesquisador estrangeiro solicitava autorização para fazer trabalho de campo em Timor Português. Foi também pessoalmente procurado por antropólogos estrangeiros interessados em desenvolver pesquisas na parte portuguesa da ilha e favoreceu as suas solicitações junto da JIU (Shepard Forman, Elizabeth Traube, Toby F. Lazarowitz etc.). Este facto demonstra que o "capital simbólico" de Cinatti era reconhecido na comunidade antropológica internacional interessada em Timor Português.

\section{Conclusões}

Desde 1946, Cinatti foi construindo um estatuto de autoridade em relação a Timor Português. O seu ascendente fundava-se, por um lado, na sua experiência directa e conhecimento do terreno, particularmente devido às suas práticas diversificadas de colecta, e no estabelecimento de uma ampla rede de contactos com cientistas de renome, através de uma abundante correspondência, envio de materiais colectados e algumas visitas recíprocas; e, por outro lado, na ausência de cientistas de campo e infraestruturas científicas nacionais em Timor Português. Na década de 1960, o seu papel de intermediário, avalizado pela JIU e pelo Ministério do Ultramar, foi uma estratégia para afirmar a sua credibilidade como o especialista imprescindível de Timor Português, mas também reforçar o prestígio e a prioridade científica nacionais, num contexto político internacional desfavorável ao império colonial português.

56 Neste artigo, procuramos mostrar a centralidade da obra de A. P. Elkin no pensamento e na aç̧ão de Ruy Cinatti, nas suas estadias em Timor e na sua aproximação à antropologia. A retórica do conhecimento desinteressado, ou melhor, do conhecimento apenas interessado no bem-estar dos timorenses (como Elkin em relação aos aborígenes da Austrália), é um dos pilares em que assenta o seu prestígio pessoal e a sua afirmação nos campos científico e do poder.

57 Até aqui, apontava-se a excursão com Mendes Correia e António de Almeida como a experiência que o motivou para as pesquisas antropológicas lato sensu. Como vimos, na 
sequência dessa excursão, Cinatti fica desagradado com a forma de trabalhar de António de Almeida e sobretudo com a sua postura política. A sua distância relativamente a António de Almeida, que também deve ser vista como uma disputa de poder relativamente a Timor Português, reflecte ainda uma visão distinta da antropologia. A falta de formação pós-graduada em antropologia cultural e social em Portugal determinou a ida de Cinatti para Inglaterra, onde a sua autoridade (de autodidacta) ganhou chancela profissional e projecção. A debilidade da antropologia social e cultural em Portugal - em termos institucionais e de profissionais habilitados -, de que Cinatti tinha aguda consciência, a relevância que atribuía ao terreno etnográfico que Timor Português constituía, e a sua falta de vocação para uma etnografia intensiva ajudam a explicar o seu contributo para a "abertura" de Timor à comunidade antropológica internacional, desde que não declaradamente hostil à posição portuguesa.

ANDERSON, Warwick. 2006. The cultivation of whiteness: science, health, and racial destiny in Australia. Durham : Duke University Press.

BOURDIEU, Pierre. 2003. Os usos sociais da ciência : por uma sociologia clínica do campo científico. São Paulo : Unesp. Publicado originalmente em 1997.

CALLON, Michel, LASCOUMES, Pierre \& BARTHE, Yannick. 2001. Agir dans un monde incertain : essai sur la démocratie technique. Paris : Seuil.

61 CINATTI, Ruy. 1985. "Conversas inacabadas [III] - Há tanta maluqueira na nossa História !”. Grande Reportagem, 20 : 40-41.

DIAS, Jorge. 1996. "Prefácio". In : Ruy Cinatti, Um cancioneiro para Timor. Lisboa: Editorial Presença. pp. 9-11.

ELKIN, A. P. 1938. The Australian aborigines: how to understand them. Sydney: Angus \& Robertson. 1953. Social anthropology in Melanesia: a review of research. London: Oxford University Press.

GOMES, Ruy Cinatti Vaz Monteiro. 1949. De Timor. Lisboa : [s.n.]. Relatório apresentado à Junta das Missões Geográficas e de Investigações Coloniais.

1950a. Esboço histórico do sândalo no Timor português. Lisboa: Junta de Investigações Coloniais.

GOMES, Ruy Cinatti Vaz Monteiro. 1950b. Explorações botânicas em Timor. Lisboa : Junta de Investigações Coloniais. 1950c. Reconhecimento preliminar das formações florestais no Timor Português. Lisboa : Junta de Investigações Coloniais. . 1956. "Em favor dos timorenses". Cidade Nova, IV série, (5) :306-310.

70 GUNN, Geoffrey C. 2009. "Timor-Leste (former Portuguese East Timor): from colonial anthropology to an anthropology of colonialism". Review (Fernand Braudel Center), 32(3) : 289-337.

71 HICKS, David. 2011a. “A pesquisa etnográfica no Timor português”. In : Kelly Silva \& Lúcio Sousa (eds.). Ita maun alin... O livro do irmão mais novo : afinidades antropológicas em torno de Timor-Leste. Lisboa : Colibri. pp. 31-45. 2011b. Depoimento sobre Ruy Cinatti, Lisboa, 28.06.2011. Entrevista de áudio concedida a Cláudia Castelo. 
2017. "Research past and research present: doing fieldwork in Portuguese Timor and Timor-Leste", In: Maj Nygaard-Christian \& Angie Bexley (ed.). Doing fieldwork in Timor-Leste. Copenhaga : NIAS Press. pp. 32-57.

HODGE, Joseph M. 2007. The triumph of the experts: agrarian doctrines of development and the legacies of British colonialism. Athens: Ohio. 2011. "Science and empire: an overview of the historical scholarship". In: Brett

M. Bennett e Joseph M. Hodge (eds.). Science and empire: knowledge and networks of science across the British Empire, 1800-1970. Basingstoke : Palgrave Macmillan. pp. 3-29.

JERÓNIMO, Miguel Bandeira \& PINTO, António Costa (eds.). 2014. Portugal e o fim do colonialismo : dimensões internacionais. Lisboa : Edições 70.

LEAL, João. 2006. Antropologia em Portugal : mestres, percursos, tradições. Lisboa : Livros Horizonte.

LEVI, Giovanni. 1989. "Les usages de la biographie”, Annales: Économies, Societés, Civilisations, 44(6) : 1325-1336.

KOHLER, Robert E. 2007. "Finders, keepers: collecting sciences and collecting practice Robert E. Kohler". History of Science, 45(4):428-454.

KUKLICK, Henrika \& KOHLER, Robert E. 1996. Science in the field. Ithaca, N.Y.: Cornell University.

MATOS, Patrícia Ferraz de. 2012. "Mendes Correia e a Escola de Antropologia do Porto." Lisboa: Tese de doutoramento em Ciências Sociais, Antropologia Social e Cultural, Instituto de Ciências Sociais, Universidade de Lisboa.

MEHOS, Donna C. \& MOON, Suzanne M. 2011. "The uses of portability: circulating experts in the technopolitics of cold war and decolonization". In: Gabrielle Hecht (ed.). Entangled geographies: empire and technopolitics in the global Cold War. Cambridge, Mass. e Londres : MIT Press. pp. 43-74.

4 O MUNDO PORTUGUÊS (org.). 1935. Roteiro do 1.ำ Cruzeiro de Férias às Colónias de Cabo Verde, Guiné, São Tomé e Príncipe e Angola : iniciativa do "Mundo Português" 1935. Lisboa : [Sociedade Industrial de Tipografia Ltda.].

OLIVEIRA, Alexandre. 2006. "Olhares sobre Timor: contextos e processos da antropologia de Timor", Lisboa: Tese de mestrado em Antropologia: Patrimónios e Identidades, Instituto Superior de Ciências do Trabalho e da Empresa-ISCTE.

RAJ, Kapil. 2016. “Go-betweens, travelers and cultural translators". In: Bernard V. Lightman (ed.). A companion to the history of science. Chichester (UK) : Wiley Blackwell. pp. 39-57. human skulls in the Portuguese empire, 1870-1930. New York : Palgrave Macmillan.

8 SCHOUTEN, Maria Johanna. 2001. “Antropologia e colonialismo em Timor português ?” Lusotopie, 157-171.

SHEPHERD, Christopher J. 2013. Development and environmental politics unmasked: authority, participation and equity in East Timor. Abingdon, Oxon: Routledge.

SHEPHERD, Christopher \& McWilliam, Andrew. 2014. "Divide and cultivate: plantations, militarism and environment in Portuguese Timor, 1860-1975”. In: Frank Uekotter (ed.). 
Comparing apples, oranges, and cotton: environmental histories of the global plantation. Frankfurt/New York : Campus. pp. 139-166.

SILVA, Hélder Lains e. 1956. Timor e a cultura do café. Lisboa : Junta de Investigações do Ultramar.

SILVA, Maria Cardeira da \& OLIVEIRA, Sara. 2013. "Cruzeiros de soberania : o primeiro Cruzeiro de Féras às Colónias". In: Maria Cardeira da Silva. Castelos a bombordo: etnografias de patrimónios africanos e memórias portuguesas. Lisboa : CRIA. pp. 261-284.

STILWELL, Peter. 1995. A condição humana em Ruy Cinatti. Lisboa : Presença. Unwin.

\section{NOTAS}

1. Este artigo é um resultado do projeto As Ciências da Classificação Antropológica em 'Timor Português' (1894-1975), financiado pela Fundação para a Ciência e Tecnologia, Portugal (Ref. HC/ 0089/2009) e do projeto Cientistas de Campo no "Cenário Luso-tropical": Conhecimento, Ideologia, Governo no Império Português tardio, financiado pela mesma instituição (Ref. IF/ 00519/2013).

2. Não era a primeira vez. Viajantes e cientistas da era vitoriana (por exemplo, Forbes e Wallace) tinham visitado Timor Leste, e o território fora uma zona de disputa científica a propósito da classificação racial dos timorenses enquanto malaios ou papuas (Gunn, 2009). Roque (2010) mostra que Timor Português nasceu como objecto relevante na etnologia lato sensu na arena internacional no século XIX.

3. Cinatti, devido às redes de relações que estabelece com cientistas, intelectuais e políticos (inclusivamente com membros do governo português), move-se numa zona de imbricação entre o campo científico e o campo político.

4. Sobre a tentativa de os impérios coloniais britânico e francês revigorarem e relegitimarem o colonialismo, no pós-Segunda Guerra Mundial, através de políticas desenvolvimentistas e do recurso sem precedentes à ciência e à tecnologia, veja-se Cooper (1997) e Hodge (2007). No caso português, essa tentativa passou também pela afirmação, perante a comunidade internacional, da unidade nacional "do Minho a Timor" e pela apropriação do luso-tropicalismo (por exemplo, Jerónimo \& Pinto, 2014).

5. Portugal, Arquivo Nacional Torre do Tombo, Arquivo Marcelo Caetano (AMC), carta de RC para MC, Lisboa, 21.10.1944, fl. 3.

6. AMC, carta de RC para MC, Dili, 17.12.1946, fl. 10-11.

7. AMC, carta de RC para MC, Dili, 13.5.1947, fl. 5.

8. Idem, fl. 6.

9. Idem, fl. 3-4.

10. Idem, fl. 18-19.

11. AMC, carta de RC para MC, Dili, 17 1946, fl. 8.

12. AMC, carta de RC para MC, Díli, 17.12.1946, fl. 9.

13. Ibidem. 
14. Portugal, Biblioteca Universitária João Paulo II, Espólio Ruy Cinatti (ERC), carta de RC para APE, Díli, 17.11.1954.

15. Austrália, Arquivos da Universidade de Sydney, carta de APE para RC, 14.02.1955.

16. ERC, carta de RC para Zé [José Cutileiro], 12.11.1963.

17. Portugal, Universidade de Lisboa, Arquivo Histórico do Instituto de Investigação Científica Tropical (AH-IICT), Proc. 277, doc. 6.

18. ERC, Cópia da carta de RC para o professor [João] Carrington da Costa, [Oxford, 1.6.61].

19. ERC, carta de RC para Zé [José Cutileiro], 12.11.1963.

20. AH-IICT, Proc. 292, vol. 1, ofício de AA, para o presidente da CE da JIU, 22.4.1964.

21. Portugal, Arquivo Histórico Diplomático, Gabinete dos Negócios Políticos, carta de RC para o presidente da CE da JIU, Lisboa, 15.9.1964, fl. 1-2.

22. ERC, carta de JF para RC, Oxford, Institute of Social Anthropology, 26.6.1968.

23. Arquivo Histórico Diplomático (AHD), GNP, cópia de informação de RC para o presidente da CE da JIU, 21.2.1966, fl. 1.

24. AH-IICT, Processo 139-CW, doc. 1.

25. ERC, carta de LB para RC, Paris, 5.9.1965.

26. AHD, GNP, cópia de inf. de RC para o presidente da CE da JIU, 21.02.1966, fl. 2.

27. AH-IICT, Proc. $139 \mathrm{CW}$, doc. 11.

28. AHD, GNP, Of. do GNP para o presidente da CE da JIU, 26.2.1966.

29. AH-IICT, Proc. n. $139-\mathrm{CW}$, doc. 43 e 56.

30. Idem, doc. 59.

\section{RESUMOS}

Neste artigo, seguimos a história de vida de Ruy Cinatti, poeta, agrónomo e (a partir de 1958) etnólogo, que viveu alguns anos em Timor Português e contribuiu para a abertura do território à antropologiamoderna.Comonaturalista e colector amador, foi tecendo uma rede científica internacional e construindo um estatuto de autoridade, que lhe permitiria aceder ao campo científico. Para esse facto, também contribuiu a rede de relações privilegiadas que mantinha no campo político. $O$ artigo destaca a influência do antropólogo australiano A. P. Elkin no interesse de Cinatti por uma antropologia aplicada ao desenvolvimento e promoção cultural dos timorenses. A debilidade da antropologia cultural e social em Portugal (ausência de institucionalização e escassez de profissionais) e o descrédito que lhe merece o trabalho do antropólogo físico António de Almeida levam Cinatti a promover ou favorecer a entrada e o trabalho de campo intensivo de antropólogos franceses e anglo- saxónicos no território, sob uma suposta tutela da Junta de Investigações do Ultramar. O Estado-império português, acossado pela crescente contestação ao colonialismo e pelas guerras de libertação em África, subscreveu a sua estratégia como forma de garantir a "ocupação científica" de Timor, a prioridade nacional e a credibilidade do país na cena internacional.

In this article we follow the life story of Ruy Cinatti, a poet, agronomist and (since 1958) ethnologist, who lived a few years in Portuguese Timor and contributed to the opening of the territory to modern social and cultural anthropology. As an amateur naturalist and collector, he established an international scientific network and built a statute of authority, which would allow him to access the scientific field. To this fact also contributed the network of privileged 
relations that he maintained in the political field. The paper highlights the influence of the Australian anthropologist A. P. Elkin in Cinatti's interest for an applied anthropology to the welfare of the Timorese. The weakness of cultural and social anthropology in Portugal (lack of institutionalization and shortage of professionals) and the discredit that the work of the physical anthropologist António de Almeida deserved led Cinatti to promote or favour the entrance and intensive fieldwork of French and Anglo- Saxon anthropologists in the territory, under a supposed guardianship of the Board of Portuguese Overseas Research. The Portuguese empire, facing growing opposition to colonialism and the wars of liberation in Africa, endorsed his strategy as a way of guaranteeing Timor's "scientific occupation", national priority and credibility on the international stage.

\section{ÍNDICE}

Keywords: social anthropology, Portuguese colonialism, Ruy Cinatti, East Timor

Palavras-chave: antropologia social, colonialismo português, Ruy Cinatti, Timor-Leste

\section{AUTOR}

\section{CLÁUDIA CASTELO}

Cláudia Castelo é historiadora, doutora em ciências sociais (sociologia histórica) pela Universidade de Lisboa. É investigadora auxiliar no Centro Interuniversitário de História das Ciências e da Tecnologia, da Faculdade de Ciências da Universidade de Lisboa, onde coordena um projecto de pesquisa sobre cientistas de campo no império colonial português tardio :

conhecimento, ideologia e decisão política. Contato : cscastelo[at]fc..ul.pt 